\title{
Congenital nephrotic syndrome with dysmorphic features and death in early infancy: Questions
}

\author{
Julien Heinrich Park • Martin Weissensteiner • \\ Oliver Wagner • Yoshinao Wada • Stephan Rust • \\ Janine Reunert $\cdot$ Thorsten Marquardt
}

Received: 11 December 2014 / Revised: 10 February 2015 / Accepted: 10 February 2015 / Published online: 7 May 2015

(C) IPNA 2015

Keywords Congenital nephrotic syndrome · Oedema .

Seizures $\cdot$ Dysmorphism

\section{Case summary}

The baby boy was the second child of Austrian parents who reported no consanguinity. His twin sibling had died at 10 weeks of gestation. Birth occurred after 36 weeks; weight, length and head circumference at birth were 2,090 g $[<3 \mathrm{rd}$ percentile $(2.5 \mathrm{~kg})], 43 \mathrm{~cm}[<3 \mathrm{rd}$ percentile $(46.3 \mathrm{~cm})]$ and $31 \mathrm{~cm}[<3 \mathrm{rd}$ percentile $(32.1 \mathrm{~cm})]$, respectively. The Apgar score was $6 / 8 / 9$. Due to respiratory distress, the newborn was transferred to the neonatal intensive care unit. He showed multiple petechiae, inverted nipples and scrotal and penile oedema. Facial dysmorphisms, such as a broad nasal bridge and distinctly low-set ears, as well as small eyes with pro-

The answers to these questions can be found at http://dx.doi.org/10.1007/ s00467-015-3070-1.

J. H. Park $\cdot$ S. Rust $\cdot$ J. Reunert $\cdot$ T. Marquardt $(\varangle)$

Klinik und Poliklinik für Kinder- und Jugendmedizin-Allgemeine

Pädiatrie, Universitätsklinikum Münster, Albert-Schweitzer-Campus

1, Gebäude A1, 48149 Münster, Germany

e-mail:marquat@uni-muenster.de

M. Weissensteiner $\cdot O$. Wagner

Abteilung für Neonatologie, Landes- Frauen- und Kinderklinik Linz, Linz, Austria

Y. Wada

Osaka Medical Center and Research Institute for Maternal and Child

Health, Osaka University, Osaka, Japan nounced hypertelorism were present. The right foot presented as pes supinatus with digitus quintus subductus.

The patient suffered from congenital nephrotic syndrome (CNS) with generalised oedema, severe proteinuria $(645 \mathrm{mg} /$ dl), hypoalbuminemia $(20.6 \mathrm{~g} / \mathrm{l})$ and low serum immunoglobulin G [IgG; on day 27: $<40 \mathrm{mg} / \mathrm{dl}$ (normal range $660-1$, $750 \mathrm{mg} / \mathrm{dl})]$. He was treated with daily protein substitutions (6 ml/kg human albumin $20 \%$ ) and IgG substitutions. High blood pressure developed. Attempts to treat the CNS with corticoids were unsuccessful.

Levels of thyroid hormones were normal at 14 days of age, but subsequently decreased: TSH 0.44 (reference $0.72-11.00$ ) $\mu \mathrm{U} / \mathrm{ml}$, free T4 0.52 (reference $0.89-2.20$ ) $\mathrm{ng} / \mathrm{dl}$ and free T3 1.05 (reference 1.95-6.04) pg/ml. Thrombocytes were low $(70,000 / \mu \mathrm{l})$.

Seizures started at 52 days of age, and electroencephalography revealed a burst suppression pattern in the fronto-central region of the right hemisphere. Due to muscular hypotonia a biopsy of the quadriceps femoris was performed, showing a predominance of type 2 muscle fibres (approx. $75 \%$ of all fibres) and relatively small type 1 muscle fibres (about $30 \%$ smaller than type 2 fibres).

At 6 weeks of age, the patient developed pneumonia and sepsis. Anuria occurred, and the boy died from kidney and respiratory failure 1 week later.

\section{Questions}

1. What is the differential diagnosis for the underlying disorder?

2. What test result should be obtained to establish the diagnosis? 